\title{
PRACTICAL SUGGESTIONS AS TO WAYS OF IMPROVING THE MATHEMATICAL PRODUCT OF THE HIGH SCHOOL.*
}

\author{
By EFfie Graham, \\ Topeka High School.
}

I would not be a true follower of the unknown quantity did I not believe that the only way to improve the mathematical product of the high school is the way by which any product may be improved, that is by eliminating its zero or negative factors and substituting for its fractional factors real integral ones. We may disagree as to the relative or absolute value of the factors but we must all admit that the rule will solve the problem, the merest statement of which we shall now undertake. What is the matter, not with Kansas, Will White has settled that, but with our high school mathematics? Many other wise good teachers shorten the radius of the circle of their self-satisfaction and complacently say, "I see nothing seriously wrong with it now. I pay no attention to what others think about restlts in my department. I am training for power." Others, more progressive, going out on a tour of inspection to colleges, schools of technology, offices and business: houses find that the results of the four years' work in our high school mathematics are not what under wiser rule they might become. No need to say this is true of all other branches. That is not the question. It certainly should not be true of our own.

Granted, then, that the product should be improved, the first thing we need is to eliminate the zero factors. Ask the average teacher to teach something in a certain term not heretofore required, and invariably the answer is, "I have no room for it. There is already too much to do in the time." There is no doubt of the truth of this; there is too much to do. Cut some of it out. Lack of quantity has never been the trouble; there is too much that lacks the excuse of future need or cultural value. What to eliminate is not mine to say, but we may consult and inquire and inform ourselves, then eliminate the things not really necessary for future work or present drill. A zero factor has no greater destroying power in a mathematical prodwct than have these dead, useless, unrelated things in our high school product.

\footnotetext{
* Read before the Kansas Mathematical Association.
} 
There are also in our mathematical course factors of fractional value. They are perhaps cultural but not practical, or practical but not cultural. Needing time and room as we do, why not substitute for these something both practical and cultural? Long lists of dull problems in simultaneous equations or many of the so-called literal equations in algebra might well be replaced by lists of physics formulæ. Omit three or four dozen quadratics where $x$ and $y$ are the unknown quantities, substituting those in which the pupil must determine on sight whether the equation is a quadratic or a linear in $R, S$, or $V$. Write the equations yourself if you do not find a suitable text. Take out a few of the problems in which tardy "B starts to overtake A" and teach the pupil to recognize the quadratic equation if written in Gaelic, and to solve it by the formula even if blindfolded and with hands tied behind his back.

Having made room for them, let us see to it that some of the newer things in mathematics get into our classes. One of the very best ways to do this is to join the Kansas Mathematical Association and subscribe for a real live mathematical magazine. ScHOOL Science and Mathematics is one of these. The best talent of our country is now represented in these publications. Inspiration, information, direction, and guidance will come to ts from this source. Even if we disagree in part we are at least awakened.

Giving the history of mathematics a part in the class room work in the proper amount and place is a marvelous interest awakener. Pupils for the first time realize the dignity of the text when learning of its classic value. They learn that the handbook of Ahmes, I700 B. C., contained a problem in arithmetical progression; that Euclid proved long ago that all angles are right angles, the fallacy of which many of them are unable to detect. These things captivate the wandering interest and create a renewed vigor in the solution of all problems. In the higher institutions of learning some of the best work in mathematics to-day is done by students who attribute their success to their suddenly awakened interest in mathematics by work of this kind done in a high school. Try it. Why not cast out ninety and nine problems in $x, y$, and $z$ in order to gain one really awakened student? Organize a mathematics club to meet after school hours or evenings and study the history and the development of mathematics, its fallacies, famous problems, etc., and 
watch results. Notice the smile that greets the statement then, that even the Egyptians could solve a quadratic.

These are only suggestions. There are many new old things in use to-day in high school; the graph, having its place as an illuminant of the quadratic, and laboratory methods, a name more formidable than suggestive. You are all familjar with these, and I only need to say, "Make room, take out the zero factors, the half value things, and substitute either those of integral value or these that will add interest to the making up of our mathematical product."

I like the idea that our high school mathematics class room ought oftener to be our mental laboratory, a place where we do things mentally; where keen thought, vivid imagination, shrewd phrasing of an abstruse proposition, nice discrimination of thought differences, have place, scope and encouragement, the teacher saying openly and frankly, "Now this is mental gymnastics. Value it, solely because it teaches you to think carefully and correctly." In geometry, "This lesson to-day is as fine a vehicle for logic as you will find when you study logic itself," or in algebra, "This is a lesson in the translation of English into algebraic symbols. Let there be no solving problems to-day; let all think, strive to express the shades of English meaning in the much desired equation." A little of this mental laboratory work, even if we neglect to find the G. C. D. by the division method, will send a class out with their heads in the air, conscious and proud of their mentality and anxious to do anything that will aid in its development.

At one time, at the original New York Chautauqua, it was the privilege of the speaker to see the Rev. Lyman Abbott arise to address an audience of eight thousand people. His subject was not announced but it was expected that he would speak on one of the many philosophical subjects of which he is master. Standing for several minutes without speaking, surveying the multitude, he said, "Friends, you may or may not sanction my action, but I never face such a crowd as this without remembering that first of all I am a preacher of the Word, a minister of the gospel, and so I shall to-night preach a straight gospe! sermon." And such it was. No metaphysical flights nor the torical periods, only the straight sweet gospel story.

It is not sacrilegious to use this story to illustrate my point: for to me, the mission of a teacher, even of a teacher of mathe- 
matics, is clearly high and helpful. While unlike the Reverend Abbott I am not thrusting aside any eloquent exposition, still like him I have a story, my gospel of the mathematics teacher, new neither to you nor to me, and lacking even the charm of rare telling. It is told often now even where two or three mathematics teachers are gathered together. Every day and every hour the fact is brought anew and with greater force to my consciousness that the "water tight compartment" method, as some call it, of serving up our algebra, geometry, arithmetic and trigonometry is all wrong. One book is studied, closed and sealed with a great seal "which is' never to be opened till the great day;" another subject is taken up, studied, closed and sealed in like manner, and so on until the last one in the course has been taken up and finished. We all know the result; our pupils, as J. N. Rice in those old Forum articles said, do not know things. They know the last term's work fairly well but not much preceding that. Oh, yes, our pupils have the power; they have gained power and that is the great end and aim of education. Granted they have gained power of a certin kind; why not the power to call up at will on being confronted with a problem its arithmetical, algebraic, or geometrical prototype, with its attendant solution?

Meeting something strange or new in the science, English or mathematics work in high school and college or in the problems of the business world, our pupils would not say if they were rightly taught, "I have never heard of that," or, "We used to do that in the eighth grade in geometry or algebra; but I have forgotten all about it." What greater manifestation of the power we hope to impart than that pupils are able to discover quickly in new problems something of which the old one was but a prototype, and be able to apply quickly and accurately their previous knowledge to its solution? Power to work is not enough to expect: Power to take the initiative, to know how to begin, how to go on, is what we must have, otherwise we may say that something is the matter with our high school mathematics.

How to do this? You are all working this out, I hope. Will parallel courses of arithmetic, algebra and geometry do it? I believe that they will do much. It is a success abroad. Failures in this country have been the result of faulty application and present environment rather than of the plan itself. It is a 
psychological fact that time and repetition are necessary elements in burning facts and methods into the memory and consciousness until the doing becomes mechanical. A boy who solves one equation a day for three hundred and sixty-five days will never forget the method; while the fellow who solves three hundred and sixty-five equations in ten days may do so. The last day before graduation a pupil should if rightly taught be able to recall without effort the important things taught him in the eighth grade. Why not? Is not our joke about his being tmable to do so rather an excuse for our failure than a justification of the fact?

Just now we ask, "When may we hope for better things?" We come up here year after year, listen, talk, agree, disagree, go home and do things in the same old way. Why not take some measures to rectify what most of us agree is an evil? A suitable text in algebra containing modern practical problems, work in graphs; with emphasis placed on the right topics for high schools and all other topics omitted would be a great thing for our high school mathematics; not a book made to sell to colleges, normai schools, private and country schools, large enough to fit the largest and to be ctit down for us. Speed the day when the Kansas Mathematical Association will stand up to be counted when a text-book of algebra is chosen.

It would be another great thing for us if the Kansas colleges would agree upon a clear-cut, definite requirement for college entrance. When the subject of college algebra may cover everything from calculus to the catechism, and a dignified college professor clothed with authority and learning may say, "Teach this for entrance or that for smooth sailing next term in my class," and when another whose college flies a pennant of another color, but who is equally wise and equally learned, says, "Not that; that belongs in college. I wish you to teach something else;" and a third requires another different preparation, please tell us just where the poor high school product or the poorer producer is? The Kansas Mathematical Association hopes to see this remedied. We are uncertain as to the outcome of some policies, but we do know that here is a tribunal that will in time settle this among other anomalous things. Our Kansas colleges will be asked to furnish definite, clear and uniform requirements in high school mathematics, and at least a week's notice of a change in the course. 
While we must have uniformity and intelligent supervision to do the best work, still wherever unhampered by uninterested and ignorant anthority, let us take up the work ourselves and do what we may toward unifying the course. If alternate days' work in algebra and geometry is not satisfactory, and we are not yet convinced that it is unsatisfactory, it is within the power of every teacher to arrange her daily program so that into each recitation aside from the daily progress made in the new subject under consideration may be introduced some review of arithmetic, algebra or geometry. Some drill in rapid multiplying, adding, and the practical arithmetical processes, in solving quadratic equations, factoring, some work in exponents, computing triangles, etc., etc., not in a haphazard way, but outlined to cover gradually the whole course so that there is always present this idea of preserving the factors that were in the prodact when it came to us, as well as adding new ones. Then with the extra time which the removal of useless work will give us, our mathematical product would hold at the time when we present it to the public or to the higher institution of learning, all the original factors raised to their highest power by continued multiplication, all the zero, fractional and imaginary factors replaced by real integral ones, all signs of operations gone, and the product reduced, simplified, ready to take its place in the great world's problem.

\title{
THE ANGLE SUM OF THE GENERAI POLYGON.
}

\author{
By J. S. Brown, \\ San Marcos, Texas.
}

Definitions: A polygon is a broken line lying in a plane, whose end points coincide. The parts of the broken line are called the sides of the polygon. Polygons are either simple or cross. A simple polygon is one, no two of whose sides cross unless produced. A cross polygon is one, two or more of whose sides cross without being produced. Any part of a cross polygon which, taken alone, is a simple polygon is called a segment.

Angle sum: The angle sum of a polygon is the sum of the angles formed on one side of the perimeter of the polygon. Hence, there are two angle sums in a polygon, corresponding 